\title{
Geographic patterns in fruit colour diversity: do leaves constrain the colour of fleshy fruits?
}

\author{
Kevin C. Burns • Eliana Cazetta • Mauro Galetti • \\ Alfredo Valido $\cdot$ H. Martin Schaefer
}

\begin{abstract}
We tested for geographic patterns in fruit colour diversity. Fruit colours are thought to promote detection by seed dispersers. Because seed dispersers differ in their spectral sensitivities, we predicted that fruit colour diversity would be higher in regions with higher seed disperser diversity (i.e. the tropics). We collected reflectance data on 232 fruiting plant species and their natural backgrounds in seven localities in Europe, North and South America, and analysed fruit colour diversity according to the visual system of birds-the primary consumer types of these fruits. We found no evidence that fruit colours are either more conspicuous or more diverse in tropical areas characterised by higher seed disperser diversity. Instead, fruit colour diversity was lowest in central Brazil, suggesting that fruit colours may be more diverse in temperate regions. Although we found little evidence for geographic variation in fruit hues, the spectral properties of fruits were
\end{abstract}

Communicated by Steven Johnson.

Electronic supplementary material The online version of this article (doi:10.1007/s00442-008-1227-3) contains supplementary material, which is available to authorized users.

\section{K. C. Burns ( $\square)$}

School of Biological Sciences,

Victoria University of Wellington,

P.O. Box 600, Wellington, New Zealand

e-mail: kevin.burns@vuw.ac.nz

E. Cazetta - M. Galetti

Plant Phenology and Seed Dispersal Research Group,

Departamento de Ecologia,

Universidade Estadual Paulista, UNESP, C.P. 199,

Rio Claro, SP 13506-900, Brazil

e-mail: eliana.cazetta@gmail.com

M. Galetti

e-mail:mgaletti@rc.unesp.br positively associated with the spectral properties of backgrounds. This result implies that fruit colours may be influenced by selection on the reflectance properties of leaves, thus constraining the evolution of fruit colour. Overall, the results suggest that fruit colours in the tropics are neither more diverse nor more conspicuous than temperate fruits, and that fruit colours may be influenced by correlated selection on leaf reflectance properties.

Keywords Coevolution - Frugivore - Plant signalling · Seed dispersal $\cdot$ Tetrahedral colour space

\section{Introduction}

Fleshy fruits are often brightly coloured and fruit colours are thought to promote their detection by seed dispersers (Kerner 1895; Ridley 1930). However, different types of seed dispersers have different visual systems and therefore perceive fruit colour signals differently. For example, many mammals (e.g. lemurs) have two retinal cone types, while primates evolved an additional, third type of retinal

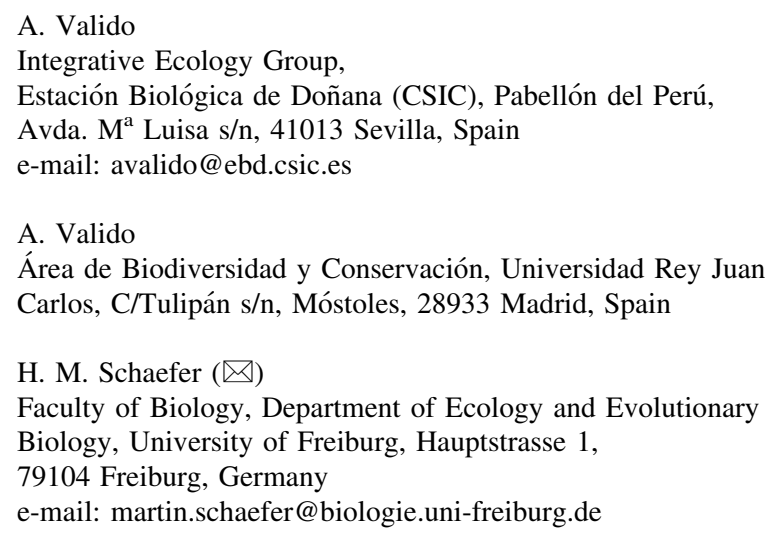


cone. Birds, fish and many reptiles have yet a fourth type of retinal cone that can detect ultra-violet (UV) wavelengths (see Kelber et al. 2003). So far, studies on fruit colouration have often categorised colours according to human vision (e.g. Janson 1983; Gautier-Hion et al. 1985), or quantified fruit colouration according to primate vision (Sumner and Mollon 2000a, 2000b; Regan et al. 2001). Both approaches may be inadequate for non-primate seed dispersers. Consequently, our understanding of the evolutionary ecology of fruit colours not dispersed by primates remains poorly resolved (Schaefer et al. 2007).

The disperser syndrome hypothesis posits that fruit traits converge to syndromes that are reliably associated with specific seed disperser types (van der Pijil 1972; Janson 1983). This hypothesis has been criticised as few animals tend to specialise on particular fruits and many fruit traits are strongly determined by phylogeny (Herrera 1985; Fischer and Chapman 1993; see Waser et al. 1996; Johnson and Steiner 2000 for pollination syndromes). However, recent phylogenetically controlled studies show that fruit colour is one of the most important fruit traits reflecting differential food selection by distinct frugivore assemblages (Voigt et al. 2004; Lomáscolo et al. 2008). If fruit colours are an adaptation to promote detection by dispersers, fruit colour diversity may be generally higher in the tropics, because tropical regions house greater diversities of seed dispersers (Gautier-Hion et al. 1985; Donatti et al. 2007). Alternatively, fruit colours may have a strong phylogenetic signal similar to other fruit traits (Jordano 1995). Therefore, fruit colour diversity may increase passively in the tropics in conjunction with increasing plant diversity. Previous analyses of spatial patterns in fruit colour have documented only weak geographic variation in fruit colours (Wheelwright and Janson 1985; Valido and Olesen 2007). However, these results may be misleading because they were based on human colour vision, which differs substantially from that of most other seed dispersers.

Frugivores rarely select fruits based on the colour of fruits per se (but see Schaefer et al. 2008). Rather, fruit conspicuousness results from spectral contrasts between fruits and their backgrounds (Burns and Dalen 2002; Schmidt et al. 2004). Selection by frugivores is therefore likely to favour colours that are perceived as strongly contrasting with their backgrounds, because strong fruitbackground contrasts are more conspicuous and increase the chances that fruits are detected (Schaefer et al. 2006). To assess fruit conspicuousness, quantitative measurements of both fruit and background reflectance are needed. As yet, no study has documented geographic patterns of fruitbackground contrasts.

Fruit-background spectral contrasts could be higher in the tropics. The tropics house greater numbers of fleshy fruited plant species, all of which must vie for the services of frugivores. A recent study documented that conspicuous fruits are more likely to be located by frugivores in a tropical vegetation community, suggesting that enhanced fruit conspicuousness may be favoured in the tropics (Cazetta et al. 2008).

An alternative explanation for geographic variation in fruit colours is that fruit reflectance properties are determined by non-adaptive processes, rather than by selection from seed dispersers. For example, fruit colours could be genetically linked to leaf reflectance properties. Under this scenario, geographic patterns of fruit colours are determined by correlated selection on leaf reflectance properties. Leaf chlorophyll concentrations, which strongly influence leaf reflectance properties, can vary substantially with latitude (Nuñez-Olivera et al. 1994; Richardson et al. 2003), thereby possibly influencing fruit colouration as well. Alternatively, it is well known that the synthesis of plant pigments in vegetative tissue may vary according to abiotic factors such as temperature (Hoch et al. 2003; Schaefer and Wilkinson 2004). Similarly, fruit and flower colours may vary with soil (Traveset and Willson 1998; Schemske and Bierzychudek 2007) or be influenced greatly by selection of flower and fruit predators (Irwin et al. 2004; Whitney and Stanton 2004). Therefore, both fruit and background colours could vary geographically according to abiotic factors, independently of selection from dispersers.

Here, we evaluate geographic variation in the reflectance properties of fleshy fruits and their backgrounds. We made spectrometric measurements on a total of 232 birddispersed fruit species inhabiting southern Germany, southern Spain, northern Florida, and south-western and south-eastern Brazil to test adaptive (increased diversity and conspicuousness of tropical fruits) and non-adaptive (trait associations between fruit and leaf colours) hypotheses of fruit colour variation. We investigated whether (1) fruit colour diversity is higher in tropical regions, (2) fruitbackground spectral contrasts differ between regions, and (3) fruit and leaf colours are correlated.

\section{Methods}

Study sites

In all areas, we collected all fleshy fruits that are consumed by birds that we encountered within the time frame indicated below irrespective of their colour. In Central Europe, fleshy fruits (hereafter fruits) and leaves were collected from August 2003 to October 2006 in two areas in south-western Germany $\left(48^{\circ} \mathrm{N}, 8^{\circ} \mathrm{E}\right)$. The first area comprises woodlands in the valley of the Rhine around Freiburg at an elevation of $250 \mathrm{~m}$, whereas the second area was located in the Black Forest at an elevation of 800-1100 m. Mediterranean fruits 
were collected in two representative areas of Mediterranean vegetation from the Iberian Peninsula during 2006-2007. One was Parque Nacional y Parque Natural de Doñana $\left(36^{\circ} \mathrm{N}, 6^{\circ} \mathrm{W}\right.$; hereafter Doñana) comprising 110,000 ha lowland vegetation $(0-100 \mathrm{~m}$ a.s.l.), and the other was the Guadahornillos valley in the Sierra de Cazorla $\left(37^{\circ} \mathrm{N}, 2^{\circ} \mathrm{W}\right.$; hereafter Cazorla) comprising 2,500 ha well-preserved Mediterranean-type montane forest (700-1,700 m a.s.l.). We sampled fruits and leaves of all species growing in these two areas except for three species from Doñana. Fruits were also collected in hardwood hammocks in the vicinity of Gainesville, Florida, in the United States $\left(29^{\circ} \mathrm{N}, 81^{\circ} \mathrm{W}\right)$ from February to April 2004. Birds are the most important seed disperser group for most of the fruits that we collected in these regions (Herrera 1984; Snow and Snow 1988; Schaefer et al. 2007). Finally, fruits were collected in two areas in Southern Brazil in January and February 2006: Ilha do Cardoso in Sao Paulo State $\left(25^{\circ} \mathrm{S} ; 47^{\circ} \mathrm{W}\right)$ is characterised by Atlantic rainforest consisting of restinga forest and lowland tropical forest with most fruits being collected in the understorey of lowland tropical forest. The Atlantic forest site is characterised by a high diversity of frugivorous birds, primates, and terrestrial mammals (Pizo 2002). The second site was located at Fazenda Rio Negro Ranch in the Pantanal, South-western Brazil $\left(19^{\circ} \mathrm{S} ; 57^{\circ} \mathrm{W}\right)$, where fruits were collected mainly in gallery forests but also in cerrado and semideciduous forest. Fruits in the Pantanal are generally dispersed by birds, mammals and fish (Donatti et al. 2007). Compared to the European locations, fruits were collected over a shorter time period in Brazil. However, since we collected all fruits that were ripe during the peak fruit season, we assume that our sample is representative for the Brazilian areas, at least during that season. We categorised fruits into two groups, those dispersed primarily by birds [termed birds in electronic supplementary material (ESM), Table S1] and those that were consumed more evenly by birds and other seed disperser types (termed mixed in ESM, Table S1) according to published information (Donatti et al. 2007; Schaefer et al. 2007), standardised observation of a minimum of $12 \mathrm{~h}$ of focal trees in Brazil (usually much longer), and the database assembled by Pedro Jordano (2001).

\section{Reflectance measurements}

We measured the reflectance spectra of at least 20 ripe fruits of each species as well as the backgrounds $(n=10)$ against which fruits were displayed (mainly leaves, but also bark and non-green coloured stems) with an Ocean Optics USB2000 spectrometer (Ocean Optics, Dunedin, FL) and a Top Sensor System Deuterium-Halogen DH-2000 (Top Sensor Systems, Eerbeek, the Netherlands) or a DT-MINIGS-2 as standardized light sources. Fruit and background samples were always collected on the same day.
Reflectance was measured as the proportion of a standard white reference tile (Top Sensor Systems WS-2). For colour measurements, we used a coaxial fibre cable (QR400-7, Ocean Optics) mounted inside a matt black plastic tube to exclude biases from ambient light. The angle of illumination and reflection was fixed at $45^{\circ}$ to minimise glare. Spectra were processed with AVANTES 6.0 (http://www. avantes.com/) or SPECTRASUITE software (http://www. oceanoptics.com/Products/spectrasuite.asp) and calculated in $5 \mathrm{~nm}$ intervals from $300-700 \mathrm{~nm}$.

\section{Eye model}

We assessed fruit signals and their colour contrasts according to avian vision because birds are the only disperser group that consumed all fruits in the various regions surveyed. Moreover, avian vision is comparatively well known, allowing us to use a well developed eye model based on the spectral sensitivities and receptor noise of the four cone types $(\mathrm{U}, \mathrm{S}, \mathrm{M}$ and $\mathrm{L})$ that determine avian colour discrimination (Vorobyev and Osorio 1998). Based on an analytical approximation of cone visual pigments and oil droplet spectra, the model calculates cone excitation values for each spectra under standard D65 illumination. We used cone excitation values to calculate the coordinate of each fruit and background spectrum in the colour space of birds, which has the shape of a tetrahedron (Goldsmith 1990; Neumeyer 1991). The results did not differ qualitatively if we used a different illumination such as forest shade for species that grow exclusively within forests (data not shown). In general, the photoreceptors of birds are remarkably similar, with variation occurring mainly in the UV-sensitive (UVS) cone (Hart 2001). We therefore based our model on the well-known spectral sensitivities of a typical passerine bird, the blue tit (Parus caeruleus), with a UVS cone (Hart et al. 2000). These results are also representative for birds with different short-wave sensitivities [visible-sensitive (VS) cone] under typical daylight viewing conditions (Schaefer et al. 2007).

Statistical analyses

Endler and Mielke (2005) advocate the use of compositional analyses to compare ecological colour patterns. We adopted a modified version of their technique to assess geographic variation in fruit colour diversity and fruitbackground colour contrasts. To evaluate ecological colour patterns using compositional analyses (Aitchison 2003), for each colour spectra the output values for each retinal cone ( $\mathrm{U}, \mathrm{S}, \mathrm{M}$ and $\mathrm{L}$ ) were first converted to relative proportions $(u, s, m$ and $l$ ). Each cone output was divided by the sum of all cone outputs for each sample to obtain relative cone outputs (Goldsmith 1990). Once converted into 
proportions, the information contained in the relative cone outputs can be simplified to three variables with no loss of information, because when $u+s+m+l=1$, then $l=1-u-s-m$. Relative cone output values were transformed following Endler and Mielke (2005) into three new variables as follows:

$x=\frac{1-2 s-m-u}{2} \sqrt{\frac{3}{2}} \quad y=\frac{-1+3 m+u}{2 \sqrt{2}} \quad z=u-\frac{1}{4}$.

The resulting variables can then be plotted in three dimensional, 'tetrahedral colour space', where $x, y$ and $z$ are Cartesian coordinates within a tetrahedron with a height $=1$.

Fruit colour diversity and fruit-background contrasts were calculated from the relative positions of points in tetrahedral colour space. Fruit colour diversity $(D)$ in each geographic region was measured as the Euclidian distance between the position of each plant species (represented by the coordinates $x, y, z)$ and the group centroid for each geographic region (represented by the coordinates $\bar{x}, \bar{y}, \bar{z}$ ):

$D=\sqrt{(x-\bar{x})^{2}+(y-\bar{y})^{2}+(z-\bar{z})^{2}}$.

Regions with greater fruit colour diversity have greater average distances to group centroids (Fig. 1). Fruitbackground spectral contrasts $(C)$ were measured as the distance between each fruit (represented by the coordinates $x, y, z)$ and their associated background (represented by the coordinates $\left.x_{\mathrm{b}}, y_{\mathrm{b}}, z_{\mathrm{b}}\right)$ :

$C=\sqrt{\left(x-x_{b}\right)^{2}+\left(y-y_{b}\right)^{2}+\left(z-z_{b}\right)^{2}}$.

Greater Euclidian distances between fruits and backgrounds in tetrahedral colour space represent higher fruit-background colour contrasts.

General linear models were used to statistically compare fruit colour diversity and fruit-background contrasts between geographic regions. Both variables $(D$ and $C$ ) were treated as dependent variables in separate analyses. Geographic region (Cazorla, Doñana, Freiburg, Black Forest, Florida, Pantanal and Atlantic Coast Forest) was treated as a fixed factor with seven levels. Plant family was also included as a coarse control for phylogenetic relatedness among replicates (i.e. species). Fruit-background contrasts were arcsine transformed to conform to homoscedasticity assumptions and both analyses were performed in SPSS (ver. 2002; http://www.spss.com/).

Endler and Mielke (2005) derive alternative statistical analyses to test for differences between the positions of groups in tetrahedral colour space. Because species in the same genus are likely to have more similar reflectance properties than species in different families, we felt that it was important to control phylogenetic relatedness in our

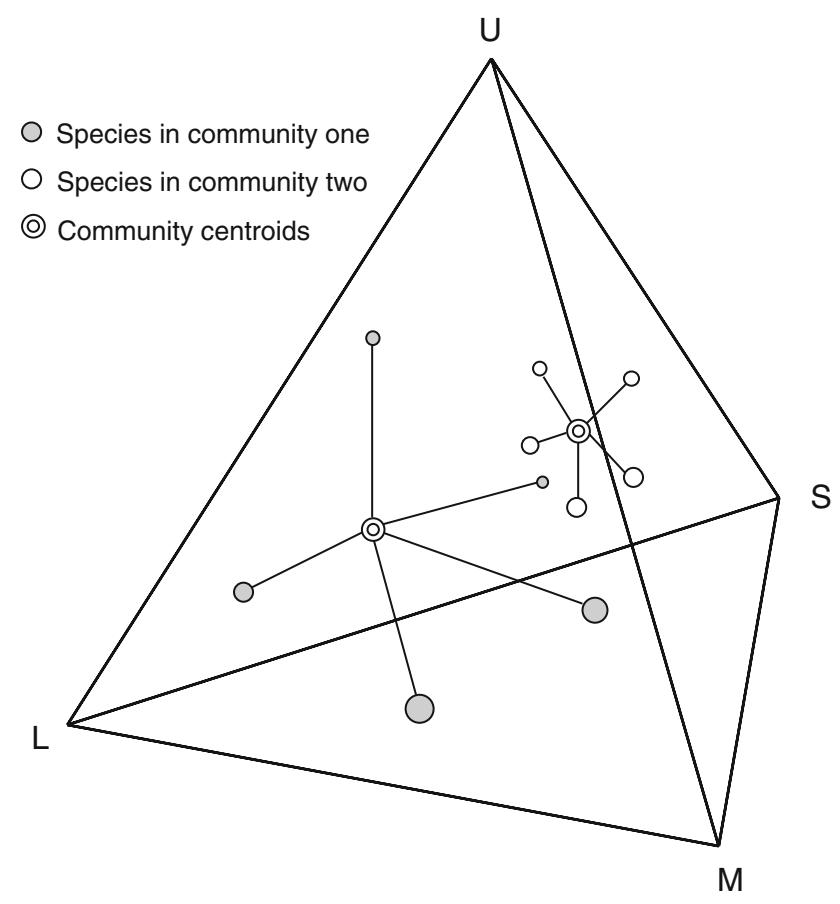

Fig. 1 Two, hypothetical, fleshy fruited plant communities (each represented by five species) plotted in tetrahedral colour space, which is bounded by the outputs of the four avian retinal cones ( $U, L, S$ and $M$ ). Plant community one has higher fruit colour diversity, or greater average Euclidian distances between species and group centroids, than plant community two (see Endler and Mielke 2005 for a more detailed description)

analyses. Such controls are not available in Endler and Mielke's (2005) randomisation techniques. In this analysis, we used taxonomy as a surrogate for phylogeny following Forget et al. (2007).

We conducted a computer simulation (i.e. null model) to test for potential relationships between the reflectance properties of fruits and their natural backgrounds. If the colours of fruits are correlated with the colour of leaves, then the points representing leaves and fruits for each species should be closely associated in tetrahedral colour space. To calculate expected differences between the colours of leaves and fruits, we conducted a computer simulation that randomly selected pairs of species from the total pool observed $(n=232)$. During each simulation replicate, a single species was randomly chosen and the position of its fruits in tetrahedral colour space was paired with the position of the leaves from a second, randomly selected species. The Euclidean distance between these two points was then calculated and taken as a single simulation replicate. Statistical comparisons were conducted for each geographic locale separately. For each locale, a random sample of distances equal to the number of species sampled was generated. This procedure was then iterated 1,000 times in Mathematica (Wolfram 1999) to generate a distribution of average Euclidean distances between fruits and leaves for 
each site. The fraction of iterations that were less than observed was taken as the one-tailed, type-one error rate in tests for non-random associations between leaf and fruit colours in tetrahedral colour space. Unlike the previous test for geographic differences in Euclidean distances between leaves and fruits in tetrahedral colour space (i.e. ANOVA testing for geographic differences in fruit conspicuousness), this analysis tests whether observed values of conspicuousness are less than expected by chance.

\section{Results}

No evidence for geographic variation in fruit colour diversity or fruit colour conspicuousness was observed (Fig. 2). Fruit colour diversity (i.e. Euclidian distances between each fruit species and the group centroid for each geographic region in tetrahedral colour space) did not differ between regions $\left(F_{6,172}=1.855, P=0.091\right)$. However, fruit colour diversity did differ among plant families, regardless of geographic region $\left(F_{53,173}=1.546\right.$, $P=0.019$ ). Fruit conspicuousness (i.e. Euclidian distances between each fruit species and its natural background) did not differ between regions $\left(F_{6,172}=0.927, P=0.447\right)$. However, it did differ among plant families, regardless of geographic region $\left(F_{53,173}=1.553, P=0.018\right)$.

While fruit Euclidean distances between the fruits and leaves of each species did not differ between geographic regions, the colour of fruits and leaves contrasted less than expected by chance. Average Euclidean distances between leaves and fruits for each geographic locale were less than average expected values generated by the null model for six of the seven study sites (Blackforest $P=0.026$, Cazorla $P=0.001$, Doñana $P=0.010$, Florida $P=0.013$, Freiburg $P=0.014$, Atlantic Brazil $P=0.003$ ). Euclidean distances between leaves and fruits were marginally different in Patanal $(P=0.079)$.

\section{Discussion}

In contrast to our predictions, fruit colour diversity was not higher in the tropics. Instead, fruit colour diversity was lower in the Pantanal than in other geographic regions.
Fig. 2 a Differences in fruit colour diversity, measured as the Euclidean distance between each fruit species and its regional mean in tetrahedral colour space, among seven geographic regions $( \pm$ SE). b Observed and expected fruitbackground contrasts in each geographic region. Contrasts were measured as the average Euclidean distance between fruit and background positions of each species in tetrahedral colour space. Black columns Observed contrasts, white columns expected values (generated by computer simulation)

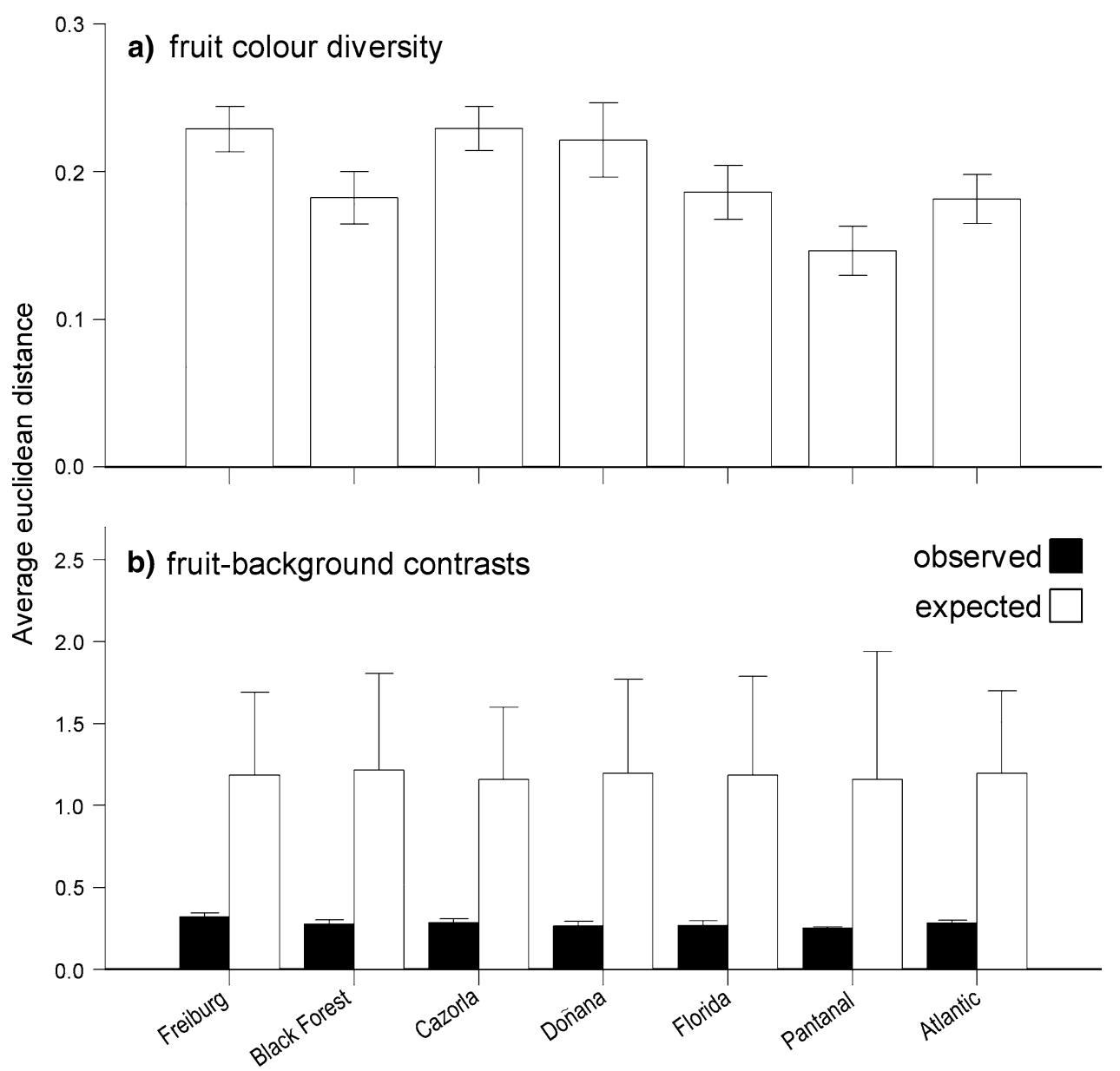

Geographic locale 
Regions that were sampled during short visits (Florida, Atlantic forest and Pantanal) did not generally exhibit lower colour diversity. Central Europe and south-western Brazil differ strongly in their seed disperser assemblages. Although mammalian seed dispersers (e.g. procyonids, canids, ursids, etc.) are present in Europe, mammalian seed dispersal is relatively unimportant compared to the tropics (Turček 1961). Conversely, mammals are, and were historically, particularly important seed dispersers in the Pantanal (Donatti et al. 2007; Guimarães et al. 2008). That birds perceive fruit colour diversity as being lower in the Pantanal might support an adaptive view on the evolution of fruit colours, because lower colour diversity occurs in a region where birds consume fruits, but other types of dispersers are common and particularly important.

Several other lines of evidence, however, suggest that fruit colours result from factors that are unrelated to seed dispersal and may instead be determined by non-adaptive processes. First, fruits contrast less against leaves in avian colour space than expected by chance. Therefore, fruit colour and geographic patterns of fruit-background contrasts might be determined by correlated evolution with leaf reflectance properties. The proximate mechanism of a linkage between fruit and leaf reflectance makes it likely that similar biochemical compounds (pigments) contribute to reflective properties in both organs. Apart from pigments, the functional correlation between fruit and leaf reflectance might also be caused by similarity in the composition and thickness of epicuticular waxes that cover both leaves and fruits. This is because waxes are important determinants of reflectance that also serve as a protection against abiotic stress factors such as desiccation, and biotic factors as microbes and fungal pathogens (Rosenquist and Morrison 1989; Richardson et al. 2003; Ribeiro da Luz 2006).

Second, the conspicuousness of fruit colours is not optimised according to avian vision (Schaefer et al. 2007). Similarly, floral colours are not optimal for insects to discriminate among flowers of different species (Chittka 1997). In both cases, non-optimality might be explained by physiological, biochemical, or phylogenetic constraints. Furthermore, birds may select fruit colours not only because of fruit conspicuousness. Fruit pigments, particularly anthocyanins, are strong antioxidants, which increase avian immune responses (Catoni et al. 2008; Schaefer et al. 2008). Also, conspicuous fruit colours signal the availability of seed resources to avian seed predators in addition to mutualistic frugivores. Avian seed predators can affect the fitness of seed plants and select for particular fruit phenotypes (Siepielski and Benkman 2008). Therefore, opposing selection from birds to increase antioxidant intake as well as from seed predators might select against increased conspicuousness.

Lastly, it is unknown whether community-wide patterns of fruit and flower colour diversity diverge from random expectation. Gumbert et al. (1999) found that floral colours only of rare species diverged from the patterns expected by null models, possibly because the colours of rare species are under greater selective pressure to send either highly recognisable signals or to mimic more common species. All of these different processes might explain why we found no geographical variation in fruit colour diversity.

Overall, the results of this study show that fruit colours do not vary geographically. Fruit and leaf colours were positively correlated across all regions. These results do not support the hypothesis that fruit colour evolution can be attributed solely to selection generated by seed dispersers. We therefore propose an alternative explanation for the evolution of fruit colours. We hypothesise that fruit colour patterns are evolutionarily linked to leaf reflectance properties, and that selection acting on the phenotype of one of these traits influences the phenotype of the other.

Acknowledgments H.M.S. was sponsored by a Deutsche Forschungsgemeinschaft (DFG) grant (Scha 1008/4-1). E.C. was sponsored by Fundação de Amparo à Pesquisa do Estado de São Paulo (Fapesp) and a Deutscher Akademischer Austausch Dienst (DAAD) fellowship. M.G. was sponsored by Fapesp and receives a research fellowship from Conselho Nacional de Desenvolvimento Científico e Tecnológico (CNPq), and E.C. a Fapesp fellowship. A.V. was supported by the Marie Curie European programme (grant MERG-CT-2004-510260), I3P [Consejo Superior de Investigaciones Científicas (CSIC)] and Acción Integrada (HA2006-0038; Ministerio de Educación y Ciencia). P. Jordano supplied information about frugivory interactions in the Mediterranean region. We are grateful to Nathaniel Wheelwright, Steve Johnson and an anonymous referee for helpful comments on the manuscript.

\section{References}

Aitchison J (2003) The statistical analyses of compositional data. Blackburn, Caldwell

Burns KC, Dalen JL (2002) Foliage color contrasts and adaptive fruit color variation in a bird-dispersed plant community. Oikos 96:463-469

Catoni C, Schaefer HM, Peters A (2008) Fruit for health: the effect of anthocyanins on humoral immune response and food selection in a frugivorous bird. Funct Ecol 22:649-654

Cazetta E, Schaefer HM, Galetti M (2008) Why are fruits colorful? The relative importance of achromatic and chromatic contrasts for detection by birds. Evol Ecol 22 (in press) doi: 10.1007/s10682-007-9217-1

Chittka L (1997) Bee color vision is optimal for coding flower color, but flower colors are not optimal for being coded-why? Isr J Plant Sci 45:115-127

Donatti CM, Galetti M, Pizo MA Giumarăes PR, Jordano P (2007) Living in the land of ghosts: fruit traits and the importance of large mammals as seed dispersers in the Pantanal, Brazil. In: Dennis AJ, Schupp EW, Green RJ, Westcott DW (eds) Seed dispersal: theory and its implications in a changing world. $\mathrm{CAB}$ International, Wallingford, pp 104-123

Endler JA, Mielke PW (2005) Comparing entire colour patterns as birds see them. Biol J Linn Soc 86:405-431 
Fischer KE, Chapman CA (1993) Frugivores and fruit syndromesdifferences in patterns at the genus and species level. Oikos 66:472-482

Forget P-M, Dennis AJ, Mazer SJ, Jansen PA, Kitamura S, Lambert JE, Westcott DA (2007) Seed allometry and disperser assemblages in tropical rainforests: a comparison of four floras on different continents. In: Dennis AJ, Schupp EW, Green RJ, Westcott DW (eds) Seed dispersal: theory and its applications in a changing world. CAB International, Wallingford, pp 104-123

Gautier-Hion A, Duplantier J-M, Quris R, Feer F, Sourd C, Decoux JP, Dubost G, Emmons L, Erard C, Hecketsweiler P, Moungazi A, Roussilhon C, Thiollay J-M (1985) Fruit characters as a basis of fruit choice and seed dispersal in a tropical forest vertebrate community. Oecologia 65:324-337

Goldsmith TH (1990) Optimization, constraint, and history in the evolution of eyes. Q Rev Biol 65:281-322

Guimarães PR, Galetti M, Jordano P (2008) Seed dispersal anachronisms: rethinking the fruits extinct megafauna ate. PLos One 3:e1745

Gumbert A, Kunze J, Chittka L (1999) Floral colour diversity in plant communities, bee colour space and a null model. Proc R Soc Lond B 266:1711-1716

Hart NS (2001) The visual ecology of avian photoreceptors. ProgRetinal Eye Res 20:675-703

Hart NS, Partridge JC, Cuthill IC, Bennett ATD (2000) Visual pigments, oil droplets, ocular media and cone photoreceptor distribution in two species of passerine bird: the blue tit (Parus caeruleus L.) and the blackbird (Turdus merula L.). J Comp Physiol A 186:375-387

Herrera CM (1984) Adaptation to frugivory of mediterranean avian seed dispersers. Ecology 65:609-617

Herrera CM (1985) Determinants of plant-animal coevolution: the case of mutualistic dispersal of seeds by vertebrates. Oikos 44:132-141

Hoch WA, Singsaas EL, McCown BH (2003) Resorption protection. Anthocyanins facilitate nutrient recovery in autumn by shielding leaves from potentially damaging light levels. Plant Physiol 133:1296-1305

Irwin RE, Adler LS, Brody AK (2004) The dual role of floral traits: pollinator attraction and plant defence. Ecology 85:1503-1511

Janson CH (1983) Adaptation of fruit morphology to dispersal agents in a neotropial forest. Science 219:187-189

Johnson SD, Steiner KE (2000) Generalization versus specialization in plant pollination systems. Trends Ecol Evol 15:140-143

Jordano P (1995) Angiosperm fleshy fruits and seed dispersers. Acomparative analysis of adaptation and constraints in plantanimalinteractions. Am Nat 145:163-191

Jordano P (2001) FRUBASE Version 3.0. http://ebd10.ebd.csic.es/ mywork/frubase/frubase.html\#vardescript

Kelber A, Vorobyev M, Osorio D (2003) Animal colour visionbehavioural tests and physiological concepts. Biol Rev 78:81-118

Kerner A (1895) The natural history of plants: their forms, growth, reproduction and distribution. Holt, London

Lomáscolo SB, Speranza P, Kimball RT (2008) Correlated evolution of fig size and color supports the dispersal syndrome hypothesis. Oecologia 156:783-796

Neumeyer C (1991) Evolution of colour vision. In: Cronley-Dillon JR, Gregory RL (eds) Vision and visual dysfunction. Macmillan, London, pp 284-305

Nuñez-Olivera R, Martínez-Abaigar J, Escudero JC (1994) Chlorophyll content of a Mediterranean shrub (Cistus ladanifer L.) over a latitude and altitude gradient in the Iberian Peninsula. Photosynthetica 30:133-142

Pizo M (2002) The seed-dispersers and fruit syndromes of Myrtaceae in the Brazilian Atlantic forest. In: Levey DL, Silva WR, Galetti $M$ (eds) Seed dispersal and frugivory: ecology, evolution and conservation. CAB International, Wallingford, pp 129-143
Regan BC, Julliot C, Simmen B, Vienot F, Charles-Dominique P, Mollon JD (2001) Fruits, foliage and the evolution of primate colour vision. Philos Trans R Soc Lond B 356:229-283

Ribeiro da Luz B (2006) Attenuated total reflectance spectroscopy of plant leaves: a tool for ecological and botanical studies. New Phytol 172:305-318

Richardson AD, Berlyn GP, Duigan SP (2003) Reflectance of Alaskan black spruce and white spruce foliage in relation to elevation and latitude. Tree Physiol 23:537-544

Ridley HN (1930) The dispersal of plants throughout the world. Reeve, Ashford, England

Rosenquist JK, Morrison JC (1989) Some factors affecting cuticle and wax accumulation on grape berries. Am J Enol Vitic 40:241-244

Schaefer HM, Levey DJ, Schaefer V, Avery ML (2006) The role of chromatic and achromatic signals for fruit detection by birds. Behav Ecol 17:784-789

Schaefer HM, McGraw K, Catoni C (2008) Birds use fruit colour as honest signal of dietary antioxidant rewards. Funct Ecol 22:303310

Schaefer HM, Schaefer V, Vorobyev M (2007) Are fruit colors adapted to consumer vision and birds equally efficient in detecting colorful signals? Am Nat 169:S159-S169

Schaefer HM, Wilkinson DM (2004) Red leaves, insects and coevolution: a red herring? Trends Ecol Evol 19:616-618

Schemske DW, Bierzychudek P (2007) Spatial differentiation for flower color in the desert annual Linanthus parryae: was Wright right? Evolution 61:2528-2543

Schmidt V, Schaefer HM, Winkler H (2004) Conspicuousness, not colour as foraging cue in plant-animal interactions. Oikos 106:551-557

Siepielski AM, Benkman CW (2008) A seed predator drives theevolution of a seed dispersal mutualism. Proc R Soc B 275:1917-1925

Snow B, Snow D (1988) Birds and berries. Poyser, Calton

Sumner P, Mollon JD (2000a) Catarrhine photopigments are optimised for detecting targets against a foliage background. J Exp Biol 203:1963-1986

Sumner P, Mollon JD (2000b) Chromaticity as a signal of ripeness in fruits taken by primates. J Exp Biol 203:1987-2000

Traveset A, Willson MF (1998) Ecology of the fruit-colour polymorphism in Rubus spectabilis. Evol Ecol 12:331-345

Turček F (1961) Oekologische Beziehung der Vögel und Gehölze. Slowakische Akademie der Wissenschaften, Bratislava

Valido A, Olesen JM (2007) The importance of lizards as frugiores and seed dispersers. In: Dennis AJ, Schupp EW, Green RJ, Wescott DJ (eds) Seed dispersal: theory and its application in a changing world. CAB International, Wallingford, pp 124147

van der Pijil L (1972) Principles of dispersal in higher plants. Springer, New York

Voigt FA, Bleher B, Fietz J, Ganzhorn JU, Schwab D, Bohning-Gaese K (2004) A comparison of morphological and chemical fruit traits between two sites with different frugivore assemblages. Oecologia 141:94-104

Vorobyev M, Osorio D (1998) Receptor noise as a determinant of colour thresholds. Proc R Soc B 265:351-358

Waser NM, Chittka L, Price MV, Williams NM, Ollerton J (1996) Generalization in pollination systems, and why it matters. Ecology 77:1043-1060

Wheelwright NT, Janson CH (1985) Colors of fruit displays of bird dispersed plants in two tropical forests. Am Nat 126:777799

Whitney KD, Stanton ML (2004) Insect seed predators as novel agents of selection on fruit color. Ecology 2004:2153-2160

Wolfram S (1999) Mathematica for windows. Wolfram Research, Urbana-Champaign, IL 